\title{
Genetics of Synthesis of $\beta$-Sitosterol Esters in Wheat and Related Species
}

THE specificity of synthesis of $\beta$-sitosterol esters in the endosperm of the allohexaploid wheat, Triticum aestioum (genomes $A B D$ ), is different from that of the allotetraploid wheat, $T$. du'um (genomes $A B$ ). Palmitate (P) followed by linoleate $(L)$ are the main esters in the hexaploid, while linoleate accounts for more than 90 per cent of the sitosterol esters in the tetraploid. Although the phenotypic difference between the two species is the presence of palmitate in $T$. aestivum, a conplete system for palmitate and linoleate $(\mathbf{P}-\mathbf{L})$ synthesis is added with the $\mathbf{D}$ genome to $T$. durn $(A B)$, because both Aegilops squarrosa $(D)$ and a synthetic $T$, spelta $(A B D)$ show the $\mathrm{P}-\mathrm{L}$ pattern (Fig. 1). 


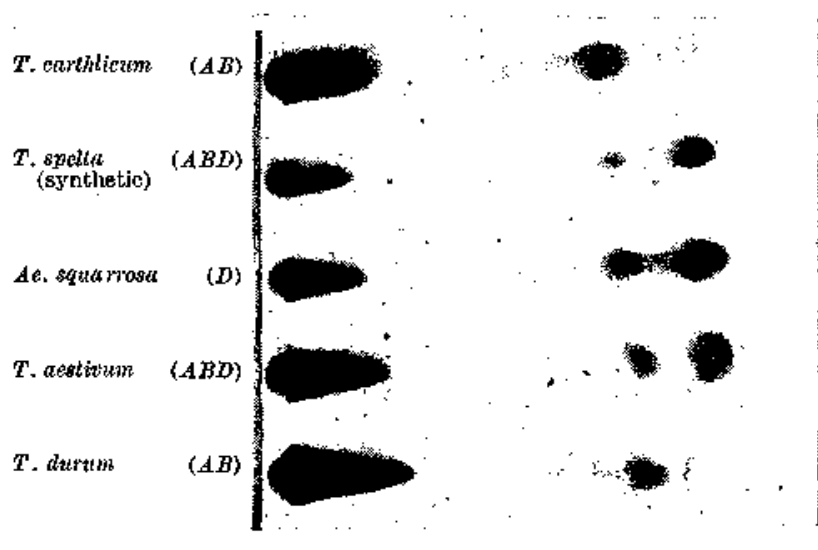

FIg. 1. R-Sitasterol ester patter'ns of $T$, earbhicum, synthetic $T$. spelta

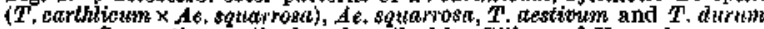
Separation method as described by Glites and Young'.

In an extensive survey of $T$. durum and $T$. aestiwum vaxieties $^{2}$, no $\mathrm{P}-\mathrm{L}$ pattern was found in the first species, but three $T$. aestivum varieties showed the $L$ pattern. Crosses between $\mathrm{L}$ and $\mathrm{P}-\mathrm{L} T$. aestivum varieties give hybrids with the $\mathrm{P}-\mathrm{L}$ pattern. In the $\mathrm{F}_{2}$ generations derived from these hybrids, segregations fit the ratio three $\mathbf{P}-\mathrm{L}$ : one $\mathbf{L}$, and the backerosses of the hybrids by the $L$ parent yield a one $P-L$ : one $L$ ratio (Table 1 ), so that sitosterol palmitate is inherited as though determined by a dominant allele at a single loeus; designed $P_{l n}$.

Table 1. SRgragation OP sITOSTEROL PALiITATR BYNTHESIS IN CROBSES B ETWEEN P-L AND L $T$. aestivun YARILTIES

\begin{tabular}{|c|c|c|c|c|c|c|}
\hline & Ob: & $r e d$ & $\operatorname{Exp}$ & & & \\
\hline Cross & P-L & L & $\mathbf{P}-\mathbf{L}$ & $\mathbf{L}$ & $x^{2}$ & $P$ \\
\hline$(\mathrm{P}-\mathrm{L} \times \mathbf{L}) \mathbf{F}_{2}$ & & & & & & \\
\hline $\begin{array}{l}\text { ('Arlana' } \times \text { 'Mara') F', } \\
\text { ('Rietti' } \times \text { 'Mara') F, } \\
\text { ('Aragon 08' } \times \text { 'Pane } 247 \text { ') }\end{array}$ & $\frac{75}{73}$ & $\begin{array}{l}25 \\
\mathbf{2 6}\end{array}$ & $\begin{array}{l}75 \\
74 \cdot 2\end{array}$ & $\begin{array}{l}25 \\
2 \pm .8\end{array}$ & $\begin{array}{l}0.60 \\
0.08\end{array}$ & $\begin{array}{l}0.95 \\
0.70\end{array}$ \\
\hline & 80 & 20 & 75 & 25 & $1 \cdot 33$ & 0.20 \\
\hline$(\mathbf{P}-\mathbf{L} \times \mathbf{L}) \times \mathbf{L}$ & & & & & & \\
\hline $\begin{array}{l}\text { ('Aragon 03' x 'MLara') } \times \\
\text { 'Mara' } \\
\text { ('Aradl' } \times \text { 'Pane 247') } \times\end{array}$ & 23 & 27 & 25 & 25 & $0+82$ & $0 \cdot 50$ \\
\hline $\begin{array}{l}\text { 'Pane 247' } \\
\text { Aragon 08' } \times \text { 'Pané 247') }\end{array}$ & 26 & 24 & 25 & 25 & 0.08 & 0.70 \\
\hline$x^{\circ}$ Pane $247^{\prime}$ & 22 & 28 & 25 & 25 & $0 \cdot 72$ & $0 \cdot 40$ \\
\hline
\end{tabular}

Both $L$ and $P-L$ varieties have the same total fatty acid pattern, which suggests that the genetic control affects the esterification of $\beta$-sitosterol and not palmitic acid aynthesis. So it is more likely from a biochemical point of view that the dominant allele determines a whole P-L system and not just sitosterol palmitate synthesis. Known fatty-acyltransferases ${ }^{3,4}$ and sterol esterases ${ }^{5}$ do not have such restricted specificity. Whether the recessive allele determines an $\mathbf{L}$ system or a non-functional P-L system cannot be discerned because segregations take place against the constant $\mathbf{L}$ background of the $T$. durum genomes.

From none to three doses of the dominant allele $P_{11}$ are possible in the endosperm, which is triploid. Patterns of sitosterol esters in hybrids resulting from reciprocal crosses between $\mathrm{P}-\mathrm{L}$ and $\mathrm{L}$ varieties (genotypes $\mathrm{P}_{1 \mathrm{n}} \mathrm{P}_{\mathrm{nn}} \mathrm{P}_{1 \mathrm{n}}$ and $\left.\mathrm{P}_{\mathrm{ju}} \mathrm{p}_{1 \mathrm{n}} \mathrm{p}_{\mathrm{n}}\right)$ did not differ significantly from that of the $\mathbf{P}-\mathrm{L}$ parent $\left(\mathbf{P}_{1 n} \mathbf{P}_{1 n} \mathbf{P}_{1 n}\right)$.

The $\mathbf{P}-\mathrm{L}$ pattern is more widely distributed than the $\mathbf{L}$ pattern in the Aegilops-Triticum group. Among the diploid species studied, Ae. speltoides (S), Ae. bicornis ( $\left.S^{\mathrm{b}}\right)$, Ae. longissima $\left(S^{1}\right)$, Ae. squarvosa $(D)$, Ae. candata $(C)$, Ae. comosa $(M)$ and Ae. uniaristata $(M \mathrm{u})$ have the $\mathrm{P}-\mathrm{L}$ system and only Ae. umbellulata $(C u), A e$ mutica $(M t)$ and $T$. monococcum $(A)$ have the $\mathrm{L}$ system. Alloploid species with the $\mathrm{L}$ phenotype are $A$ e ovata $\left(C_{\mathrm{u} M O}\right)$, Ae. columnaris $(C \mathrm{u} M \mathrm{c})$, the $A B$ tetraploid wheats $\left(T . d u t^{\prime} u m, T\right.$. turgidum, $T$, polonicim, T. carthticum) and $T$. timopheevi $\left(A B^{\prime}\right)$. The remaining alloploids included in our study, Ae. bianciatis $\left(C^{u} M \mathrm{~b}\right), A e$ triatistata $\left(C^{\mathrm{u}} \mathrm{M}\right)$, Ae. triuncialis $(C \mathrm{C})$. Ae. variabilis $(C u S v), A e . c r a s s a(D M \mathrm{or}), A e$, ventricosa $(D M v)$, Ae. cylindrica $(D C)$ and Ae. juvenatis ( $\left.D C^{c} M^{\prime}\right)$ have the $\mathrm{P}-\mathrm{L}$ phen otype.

According to the scheme of currently accepted cyto. genetic relationships between the species of this group ${ }^{6,7}$, the $\mathrm{L}$ phenotype alloploids have the pivotal genome $(A$ or $O$ ) with an $\mathbf{L}$ system and the second parental genome $(B=S$, or $M)$ with a $\mathrm{P}-\mathrm{L}$ system. Because other alloploid combinations, natura I as well as synthetic, have the $\mathbf{P}-\mathbf{L}$ phenotype, the cases of $\mathrm{L}$ phenotype may result from loss of the P-L system subsequent to the formation of the alloploid. The existence of duplicate genetie activity for sterol ester synthesis in the aloploid would permit such a loss. This would be consistent with what has been established by means of genome analysis: that the pivotal genomes in the Aegitops-Tyiticum alloploids are identical with known diploid analysers, while the additional genomes are extensively modified and only partially homologous with any known diploid. The absence of $\mathbf{P}-\mathbf{L}$ phenotypes in the tetraploid wheats studied seems to indicate that the loss of the P-L system must have occurred early in their evolution.

I thank Professor E. Sanchez-Monge for helpful discussions and for the $\mathrm{F}_{2}$ samples.

\section{Franctsco Garofa-OLmEdo}

Instituto Nacional de Investigaciones Agronómicas, Madrid, Spain.

Recelved Oetober 7, 1968 .

1 Gilles, K. A., and Young, Y. L., Ccteal Chem., 41, 502 (1964)

García-Faure, R., Gareía-Oimedo, F, and Vallejo, J. Bi, J. Sci, Food Agric., 19, 822 (1038).

o Kormberg, A. and Pricer, W. I., J. Biol. Chem., 204, 345 (1953).

+Wejss, S. B., Kennedy, E. P., and Kiyasu, J. Y., J. Biol. Chenk, 285, 40 (1960).

'Hernandez, H. H., and Chalkoff, I, L., J, Biol. Chem, 228, 447 (1957)

' Kihara, H., Indiur J. Genet., 86, A, I4 (1906).

'Zohary, D., Proe. Second Intern. Wheat Genetics Symp., Hereditas, Suppl. 2, 207 (1966).

- Kiliara, H., Cotologia, 19, $386(1954)$. 